\title{
Uptake of the MUST screening tool for inpatients in a Teaching Hospital: an audit of progress to date
}

\author{
E. Barthorpe, J. McLaughlin, B. Kuczynska and K. Farrer \\ Salford Royal NHS Foundation Trust, Stott Lane, Salford, Manchester M6 8HD, UK
}

The Malnutrition Universal Screening Tool (MUST) has been designed to help identify adults who are malnourished or at risk of developing malnutrition. Effective identification and nutritional intervention is known to improve clinical outcomes for patients ${ }^{(1)}$. The patient population admitted to the teaching hospital is drawn from a local area of high socioeconomic deprivation; therefore effective screening and intervention needs be a priority for the organisation.

MUST was introduced across the Trust in July 2006. Screening should be completed within $24 \mathrm{~h}$ of admission, as recommended by National Institute of Clinical Excellence ${ }^{(2)}$. The Electronic Patient record was audited in April 2007, (see cycle 1 in the Table). At the time these results compared unfavourably with completion of Waterlow Scores (57\% completed within $24 \mathrm{~h}$, $87 \%$ during their hospital admission. Given the initial audit results, MUST was launched as a Key Performance Indicator (KPI) with the support of hospital matrons and ward managers. A repeat audit was then undertaken after 3 months (see cycle 2 in the Table).

\begin{tabular}{|c|c|c|c|c|c|c|}
\hline & \multicolumn{3}{|c|}{ Cycle 1} & \multicolumn{3}{|c|}{ Cycle 2} \\
\hline & $\begin{array}{l}\text { MUST scored } \\
<24 \mathrm{~h}(\%)\end{array}$ & $\begin{array}{c}\text { MUST scored } \\
\text { during admission }(\%)\end{array}$ & $\begin{array}{c}\text { High MUST } \\
\text { score }(\%)\end{array}$ & $\begin{array}{l}\text { MUST scored } \\
<24 \mathrm{~h}(\%)\end{array}$ & $\begin{array}{c}\text { MUST scored } \\
\text { during admission }(\%)\end{array}$ & $\begin{array}{l}\text { High MUST } \\
\text { score }(\%)\end{array}$ \\
\hline All patient areas & 39 & 74 & 23 & 45 & 79 & 17 \\
\hline Adult medicine & 31 & 77 & 18 & 43 & 80 & 27 \\
\hline Elderly medicine & 44 & 94 & 27 & 55 & 98 & 22 \\
\hline General surgery & 60 & 87 & 16 & 70 & 83 & 23 \\
\hline Trauma and orthopaedics & 51 & 66 & 0 & 60 & 78 & 4 \\
\hline Neurology/neurosurgery & 14 & 38 & 11 & 23 & 52 & 12 \\
\hline Dermatology & 67 & 100 & 11 & 65 & 95 & 0 \\
\hline Other & 42 & 75 & 27 & 41 & 83 & 18 \\
\hline
\end{tabular}

Although completion of MUST improved across the Trust, this was only marginal from $39 \%$ to $45 \%$ within the desired $24 \mathrm{~h}$ of admission. Although $79 \%$ of patients were screened at some point during admission, this delay may have an adverse clinical impact on outcomes in acutely unwell, trauma and preoperative patients. Elderly medicine, general surgery and the regional dermatology service were most thorough in their compliance with screening. A detailed analysis is now required to understand the demographics and diagnostic categories of the patients not screened, and to address the reasons for non-compliance. Clearly there is scope for improvement; this will be co-ordinated by the nutrition steering group for the organisation.

1. Stratton RJ et al. (2004) Br J Nutr 92, 799-808.

2. NICE (2006) Nutrition Support in adults: oral supplements, enteral tube feeding and parenteral feeding. Guideline 32 London: Department of Health. 